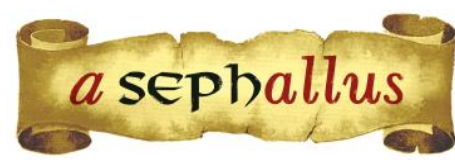

Revista aSEPHallus de Orientação Lacaniana

Núcleo Sephora de Pesquisa sobre o Moderno e o Contemporâneo

ISSN 1809 - $709 \mathrm{X}$

\title{
Percursos e entraves dos psicanalistas nos hospitais ${ }^{1}$
}

Juliana Andrade Salgado

Orcid: 0000-0003-3256-7856

Graduada em Psicologia pela Universidade Federal de Juiz de Fora (Juiz de Fora, Minas Gerais, Brasil) Pós-graduanda em Psicanálise, Laço Social e Saúde Mental pela Faculdade Machado Sobrinho (Juiz de Fora,

Minas Gerais, Brasil)

E-mail: salgadojuliana1@gmail.com

\begin{abstract}
Alinne Nogueira Silva Coppus
Orcid: 0000-0002-4278-3707

Psicanalista

Doutora em Teoria Psicanalítica/UFRJ (Rio de Janeiro, Brasil) Professora Associada do Departamento de Psicologia da UFJF (Juiz de Fora, Minas Gerais, Brasil) Coordenadora da Clínica de Psicologia Aplicada / CPA da Universidade Federal de Juiz de Fora / UFJF (Juiz de

Fora, Minas Gerais, Brasil)

E-mail: alinnerj@terra.com.br
\end{abstract}

\begin{abstract}
Resumo: Os psicanalistas estenderam sua prática para além do consultório, fazendo-se presentes em diversos contextos institucionais. Um desses novos contextos é o hospital. O presente artigo realizou um levantamento de referências bibliográficas que abordam a inserção da prática psicanalítica nos hospitais nos últimos anos. Apresentamos como ocorreu o movimento de expansão da escuta psicanalítica bem como o que a autorizou nesse novo campo. No contexto brasileiro, verificamos a presença de alguns entraves para que essa prática se solidificasse - alguns superados, outros não. Recolhemos os efeitos da sustentação do discurso do analista no hospital e apresentamos uma intervenção clínica realizada nesse contexto.
\end{abstract}

Palavras-chaves: Psicanálise; Hospital; Discurso; Entraves

Paths and obstacles of psychoanalysts in hospitals: Psychoanalysts have extended their practice beyond their cabinet, making themselves present in several institutional contexts. One of these new contexts is the hospital. This paper conducted a survey of the writings that address the inclusion of psychoanalytic practice in hospitals in the past years. We present how the movement to expand psychoanalytic listening took place and what allowed it in this new field. In the Brazilian context, we have verified the presence of certain obstacles to the consolidation of this practice - some have been overcome, others have not. Based on the collected material, we report the results achieved by sustaining the analyst's discourse in the hospital and also present a clinical intervention performed in this same context.

Keywords: Psychoanalysis; Hospital; Discourse; Obstacles.

Chemins et obstacles des psychanalystes dans les hôpitaux : Les psychanalystes ont étendu leur pratique au-delà du cabinet, se rendant présents dans des contextes institutionnels divers. L'un de ces nouveaux contextes est l'hôpital. Cet article a réalisé un recueil de références bibliographiques, qui traitent de l'insertion de la pratique psychanalytique dans les hôpitaux au long des dernières années. Nous présentons comment s'est déroulé le mouvement d'expansion de l'écoute psychanalytique ainsi que ce qui l'a autorisé dans ce nouveau champ. Dans le contexte brésilien, nous avons vérifié la présence d' obstacles à la solidification de cette pratique - certains déjà surmontés, d'autres non. D'après la bibliographie recueillie, nous réunissons les effets du discours soutenu par l'analyste à l'hôpital et nous présentons une intervention clinique réalisée dans ce contexte.

Mots clés: Psychanalyse; Hôpital; Discours; Obstacles. 


\section{Percursos e entraves dos psicanalistas nos hospitais}

Juliana Andrade Salgado \& Alinne Nogueira Silva Coppus

\section{Introdução}

Ainda em 1910, Freud reconhece que limitar a prática psicanalítica aos consultórios é reduzi-la em seu potencial. Propõe, então, que os analistas não se furtem aos novos desafios que a cultura e o discurso da ciência oferecem à clínica psicanalítica (Coppus \& Netto, 2016, p. 90). Além disso, reinventar a psicanálise, para além dos consultórios, impôs-se como uma demanda dos próprios analistas. Vemos outros espaços nos quais o sofrimento psíquico se faz presente, o que assinala a necessidade de extensão da psicanálise. É Lacan quem formaliza este movimento de "extensão" enquanto prática, sem se descolar do que ocorre na psicanálise em "intensão", ou seja, sem se descomprometer com a fundamentação teórica e com os princípios psicanalíticos (Machado \& Chatelard, 2012, p. 456). É também Lacan quem escreve o discurso do analista, demarca seu lugar enquanto função e destaca seu encargo de fazer circular a palavra na direção do desejo: firma o valor e as consequências de sustentar uma presença simbólica em detrimento de uma presença física (Batista \& Rocha, 2013, p. 26) e, assim, redimensiona o futuro da psicanálise (Figueiredo, 2000, p. 33).

As formulações de Lacan surgem, desta forma, na contramão da ideia de alguns analistas, que, partindo de uma leitura simplista do texto de Freud, Sobre o início do tratamento (1913/1996a), tomam as condições de análise como regras, como garantias quanto à execução da prática. Estas regras devem ser cumpridas rigorosamente: número de sessões, regularidade, tempo de sessão, uso do divã... A esse conjunto de normas convencionou-se chamar de setting. Acreditava-se que, seguindo estas regras, a legitimidade e o bom funcionamento da psicanálise estariam garantidos (Machado \& Chatelard, 2012, p. 457). Lacan, retoma a teoria de Freud e nos lembra que a única regra, a regra fundamental, é a associação livre e, com isso, retira a psicanálise do âmbito das normas para situá-la no campo da ética. Muito menos imaginarizado, surge assim, o dispositivo analítico que, como tal, não depende de uma configuração particular e circunstancial (Machado \& Chatelard, 2012, p. 457). Ele depende de que o analista consiga sustentar o que mais tarde Lacan nomeou de discurso do analista.

Afinal, o que possibilita que o trabalho seja realizado não é o espaço físico nem o mobiliário, mas a associação livre, a transferência, o posicionamento do psicanalista diante da mesma, sua escuta e seu direcionamento. 0 que se exige é que se estabeleça um espaço discursivo (Machado \& Chatelard, 2012, p. 457). Concebida enquanto um uso particular da palavra, o exercício da psicanálise traz consequências para quem se submete a esse discurso e pode ser conjugada em outros espaços (Morais, Rei \& Nicolau, 2009, p. 3), desde que não comprometa sua ética, que prima por fazer surgir um sujeito que se responsabilize por seu desejo (Coppus \& Netto, 2016, p.90). 
Autorizada, desta forma, a extrapolar o espaço dos consultórios, ao ser inserida no contexto hospitalar, fora das circunstâncias que Ihe é habitual, a psicanálise encontra características e demandas diferentes. Ela convida o analista a questionar os limites da mesma, convoca-o a refletir sobre sua prática de escuta, a respeito do que precisaria e poderia ser alterado sem descaracterizá-la de ser uma escuta analítica. Esta prática, apesar de preservar o cerne da teoria psicanalítica ao eleger como pilares os mesmos conceitos fundamentais previamente destacados por Lacan em 1964/1988 (inconsciente, repetição, transferência e pulsão), não permite uma mera transposição do funcionamento clínico, uma conversão do leito em divã (Moura, 2000, p. 31). Entre os atributos que se alteram e os que se mantêm, observa-se que não há, na maioria das vezes, nem o espaço físico de praxe nem tempo suficiente para o andamento de uma análise, mas que os elementos presentes nos dispositivos clínicos, em contrapartida, são preservados. Há uma demanda de fala e há aquele que escuta, há transferência, atenção flutuante e associação livre e, assim, o dispositivo analítico se constitui. Vemos que se para a constituição do dispositivo analítico não é necessário um formato previamente estabelecido, para o sujeito do inconsciente; também não é necessário um lugar e um tempo para que ele apareça, estes se encontram onde o sujeito fala: no jogo significante que localiza sua divisão e seu modo de gozo. Como já disse Freud (1923-1925/1996b, p. 256), os aspectos mais gerais da vida inconsciente estão presentes em toda parte. Resta dar espaço e valor a eles, recolher seus efeitos e trabalhar a partir dos mesmos.

Sabendo que o inconsciente é atemporal e que está sempre presente na cadeia discursiva, não há porque questionarmos a possibilidade de uma escuta analítica inserida no contexto hospitalar (Torezan \& Rosa, 2003, p. 90). Não possuir o habitual setting, não significa, desta forma, não ter lugar para a atuação analítica. Contudo, isso pode refletir na falta de um espaço simbólico no funcionamento institucional que precisa ser levado em consideração. Machado e Chatelard (2012, p. 463) alertam sobre a possibilidade de a escuta analítica ser atropelada inclusive pela via humanista, que sustenta um ideal de conforto e amparo a ser alcançado. Tomados como princípios institucionais, acabam por escamotear a singularidade dos pacientes e ensurdecer a escuta analítica. De certa forma, atuar em instituições é estar adstrito a elas (Batista, Decat de Moura \& Borges de Carvalho, 2011, p. 40). Mas, se por um lado, o analista encontra subsídios teóricos para sua atuação, por outro, depara-se com questões práticas e hierárquicas que podem vir a ser verdadeiros obstáculos, inviabilizando sua atividade e fazendo desaparecer o seu lugar (Morais et al., 2009, p. 6). Vejamos como isso começou.

\section{Um lugar para o sem lugar}

No Brasil, foi a partir da última década do século XX que se deu o crescimento da prática psicanalítica nos hospitais gerais. Em seu artigo, Machado e Chatelard (2012, p. 453) se propõem a apresentar um panorama desta época e deparam-se com certa dificuldade em encontrar tanto fontes bibliográficas que reportem a este momento, como materiais que digam sobre a função do analista 
nesses espaços. Sônia Alberti, Consuelo Pereira de Almeida e Marisa Decat de Moura, precursoras na área, iniciaram suas práticas na década de 1970 e, apesar de estarem em cidades diferentes, encontraram dificuldades similares na sustentação do trabalho do analista em hospitais. Naquele contexto, pensar a presença da psicanálise nos hospitais, sustentada por psicólogos com formação psicanalítica era inviável. Foi preciso muito investimento para a realização de seus trabalhos.

A entrada da psicologia e da psicanálise nos hospitais foi marcada por uma submissão à clínica médica. Assim, a psicanálise só aparecia, timidamente, sob a roupagem da psicologia. Esta tímida presença era, por sua vez, rejeitada tanto pelos médicos, apreciadores dos dados quantificáveis, quanto pelos próprios psicanalistas que, pela falta de formalização teórica juntamente com as resistências pessoais, apresentavam dificuldades para tomar a psicanálise fora do enquadre clássico, separando a clínica psicanalítica do trabalho na instituição. Sem a formalização desta prática, em construção, ocupar o lugar de analista nos hospitais era - e ainda é! - uma aposta.

Machado e Chatelard (2012, p. 465) concluem que os entraves à prática psicanalítica nos hospitais estão presentes desde o início - alguns superados, outros não. Desta forma, a entrada do psicanalista no hospital não implica em sua inserção efetiva nem definitiva. Diante deste lugar não demarcado, é preciso construí-lo permanentemente. Assim, torna-se difícil para a equipe, para os pacientes e para os próprios psicanalistas, identificarem o que cabe ao analista nesse contexto. Ele é chamado a responder às situações de impasses, de ajustamento dos pacientes aos imperativos médicos ou institucionais, e, sobretudo, ele é convocado a sanar as crises e urgências (Batista \& Rocha, 2013, p. 26-27), ou seja, chamado a se fazer presente em situações em que "nada mais pode ser feito", atribuindo-se a ele a especialidade das "causas perdidas" (Moura, 2005, p. 9). Se, muitas vezes, as instituições hospitalares não compreendem de imediato onde devem localizar a psicanálise, os pacientes e seus familiares tampouco.

"Eles não sabem que estamos trazendo a peste", foi o que disse Freud, em 1909, quando desembarcou na América do Norte, estendendo sua teoria para além do continente europeu. Difundir o discurso psicanalítico em um território estrangeiro, tal qual Freud, é o que faz o analista no hospital. Brincamos que aqui não trazemos a peste - audácia até para os mais otimistas - mas o espaço para que se fale dela.

Pela via da pressa da cura, da urgência e da eliminação da dor, pacientes, familiares e outros profissionais chegam ao analista em busca de um saber sobre o que the acomete. O sujeito só sabe, de fato, o que um psicanalista pode oferecer quando está diante de um (Moura \& Souza, 2007, p. 129). Não cabe ao analista, portanto, corresponder a todas as demandas que the são dirigidas, tarefa impossível, mas dar a elas um espaço para que ecoem. O analista escuta, acolhe, maneja e apura cada uma das demandas que a ele chega. Seja pelo paciente, que reclama dos serviços prestados, pela família, que o solicita a todo momento ou pela própria equipe, que pede ajuda na "adequação" do paciente ao tratamento, as demandas chegam ao psicanalista com diferentes formas e conteúdos, chegam mascaradas, em forma de perguntas objetivas, insatisfações e até de agressividade - chegam 
como podem. $\mathrm{O}$ que todas têm em comum é a busca de soluções para o sofrimento (Figueiredo, 2000 , p. 47). Não raro, o que fica para o analista, é o que sobrou dessas demandas, o que ficou sem resposta (Figueiredo, 2000, p. 170). É, pois, sustentando este espaço de escuta que o analista e, em última instância, o paciente e sua família, conseguem de fato localizar qual é a dificuldade para além das queixas (Batista \& Rocha, 2013, p. 32), tornando possível, assim, a identificação da demanda - se de atenção, de amor, ou até de uma escuta analítica.

É preciso estar lá para que se possa conhecer o que é possível e o que não é, para que os limites da prática se apresentem (Batista \& Rocha, 2013, p. 29). Na medida em que passa a ocorrer fora do setting que the é habitual, a psicanálise se refaz e se recria, adentra novos espaços e instituições, quebra domínios exclusivos e rompe com paradigmas dominantes (Rinaldi, 2002, p. 5). A psicanálise avança, conversa com outros campos, permite um giro nos discursos e, com isso, que os personagens mudem de lugar. É o que veremos a seguir.

\section{Na labuta da escuta: do discurso do mestre ao lugar do analista}

Ao adentrar nas instituições hospitalares, onde impera o discurso do mestre, regido por quem se acredita sabedor, o discurso do analista mostra sua distinção e firma sua relevância ao convidar o paciente a falar sobre sua dor, sobre o que lhe acomete.

Estes discursos, do mestre e do analista, são apresentados por Lacan em seu Seminário intitulado O Avesso da Psicanálise (1969-1970/1992). Nele, Lacan expõe os quatro discursos (a saber: discurso do mestre, discurso da histérica, discurso universitário e discurso do analista) como diferentes formas de laço social e os distingue a partir da estrutura de suas configurações. Em cada um dos discursos há um interveniente (o agente) que endereça ao outro (sobre quem incide a ação) a produção de uma verdade. Assim é a fórmula. Ela situa um momento marcado por uma ordem específica. Um quarto de giro se faz e as posições tomam novos lugares, estabelecendo assim, um novo tipo de laço. Estas posições são ocupadas pelo S1 (significante mestre), pelo S2 (saber), pelo \$ (sujeito) e pelo a (objeto causa de desejo).

$\mathrm{O}$ discurso do mestre será aquele em que o lugar do interveniente será ocupado pelo $\mathrm{S} 1$, o mestre, e que visará o S2, o saber. Saber este que, na medida em que pretende contemplar uma verdade, única, replicável a todos os corpos, prescinde do que há de singular em cada um deles. Esta operação produz, desta forma, uma sobra, um resto, $a$, causa de desejo. A verdade que se alcança, é a verdade do sujeito, $\$$, com sua divisão marcada pelos significantes mestres.

O analista, por sua vez, enquanto recusa o lugar de mestria e assume o lugar de resto, $a$, estabelece um discurso através do qual se endereça ao sujeito dividido, \$, convocando-o à produção dos próprios significantes mestres, S1, para que alcance um saber, S2, sobre sua verdade, ou seja, o que o causa. O discurso do analista propicia, desta forma, que a partir deste encontro com outros significantes, S2, o sujeito dê novos sentidos para aquilo que o marca. 
O que podemos desdobrar disto é que enquanto a maioria dos profissionais de saúde que habitam o hospital, opera a partir do discurso do mestre, colocando em disjunção o sujeito e seu sintoma, destituindo o saber de um sobre o outro, o analista intervém exatamente neste ponto, unindo e problematizando a relação entre o sujeito e seu sintoma, o que o particulariza e o sustenta, numa relação que se faz presente através da própria demanda dos pacientes por, poderíamos dizer, um tratamento semântico, um complemento de sentido (Miller, 1999).

Antes de se deter no que aparece no corpo adoecido, o analista se intriga em relação à forma com que esse sujeito habita e trata esse corpo. Operando a partir da realidade psíquica, o analista recolhe os efeitos de sujeito que o paciente deixa transparecer nas formações do inconsciente (Coppus \& Netto, 2016, p. 96) e os coloca em cena. Se os tropeços da fala são uma das formas de manifestar o inconsciente, a psicanálise os toma como possibilidade de revelar uma outra dimensão da queixa (Figueiredo, 2000, p. 43).

Ao descrever os discursos do mestre e do analista sob uma perspectiva comparativa e até antagônica, retoma-se a constatação de Lacan (1969-1970/1992, p. 81) de que são um o avesso do outro. Não se trata de demonizar a posição do mestre. Pensamos que é necessário, em muitas situações, que alguém da equipe ocupe esse lugar. Em $A$ Terceira (1974/1980, p. 5) Lacan diz que a finalidade do discurso do mestre é fazer com que as coisas caminhem no mesmo passo para todos. Ou seja, a suspensão do sujeito representa uma necessidade de ordem metodológica para que este discurso se estabeleça. $O$ que se pretende aqui é ressaltar as consequências de que este seja o único destino para o sujeito, qual seja, que o que o singulariza não tenha lugar. 0 que se pretende, com o discurso do analista, é justamente oferecer a este sujeito outras posições, a possibilidade de estabelecer uma outra relação com seu sofrimento, a doença, a possibilidade da morte, a vida.

Engana-se quem pensa que o paciente é necessariamente o acamado. Por vezes, o analista vê-se posicionado entre o médico e a equipe (Batista et al., 2011, p. 38), o médico e o doente. Não como alguém que faz barreira ou ponte, mas como alguém que esteja tão próximo de um quanto do outro, que trabalha junto ao leito e também junto à equipe. Ouve ambos: aquele que fala de si e aquele que fala sobre a doença e, por fim, atua considerando cada um deles no processo de tratamento. Paciente, família e equipe estão em um só tempo incluídos no cenário da escuta analítica e sua intervenção pode possibilitar que cada um tenha o seu espaço (Batista et al., 2011, p. 113).

Assim, as demandas aparecem não só de diferentes formas e conteúdos, mas de lugares diversos. Diante delas, o analista poderá fazer semblante de mestre ou se utilizar do discurso universitário, por exemplo, desde que tenha na passagem de um discurso ao outro um propósito, uma aposta na produção de algum efeito. A posição do analista não se reduz unicamente ao discurso do analista. É na fenda entre os discursos que o analista também pode se encontrar, propiciando o giro, o caminhar... até onde cada sujeito queira ou possa chegar (Moura \& Souza, 2007, p.129).

Para que a psicanálise pudesse surgir, Freud, como médico, teve de abrir seus ouvidos para uma outra escuta (Coppus \& Netto, 2016, p. 89) e, ao escutar sem antecipar significados, em sua 
douta ignorância, permitiu que o sujeito começasse a se escutar (Moura, 2005, p.91), para, em seguida, convidá-lo a trabalhar. É com esse posicionamento que o analista constrói, todos os dias e, diante de cada sujeito, um lugar.

\section{Possíveis efeitos de um encontro com o analista}

Ocupando este lugar de quem possibilita ao sujeito falar sobre sua dor, reconhecendo-a como verdadeira e sabendo dos efeitos que tem sobre seu corpo, o encontro com um analista pode ser determinante no destino que será dado ao sofrimento. Ao dar lugar à fala, o analista propicia que seja inscrita na história de vida do sujeito, aquilo que ele diz e até o que não diz. Sendo assim, o sentido que terá o adoecimento para cada sujeito, jamais será o mesmo. 0 encontro faltoso com o real deixa marcas únicas. Quadros clínicos idênticos apresentam efeitos diferentes e particulares, tomando a hospitalização, para cada um, um sentido singular.

Se cada experiência de adoecimento é única, o encontro com o analista e o uso que o sujeito fará dele, igualmente (Batista et al., 2011, p. 121). A psicanálise é feita no um a um: tomar cada caso como se fosse o primeiro, eis o princípio freudiano. O que permite trazer ao centro a verdade do sujeito é perceber o original e o novo trazido por cada paciente (Morais et al., 2009, p. 5), através da escuta ímpar do sofrimento. Trata-se de uma clínica que inclui a imprevisibilidade em cada circunstância, a surpresa, e, na via oposta do processo de padronização do cuidado do paciente, possibilita desobjetificá-lo do saber científico e torná-lo mais que mero produto do discurso da ciência (Rinaldi, 2002, p.12).

A objetificação do paciente pelo saber científico é facilitada pelo contexto de hospitalização o distanciamento do círculo social, dos pertences e da rotina, a padronização do cuidado, a submissão às regras impostas pela condição do adoecimento (Torezan \& Rosa, 2003, p. 85)... A isso sucedem-se interferências na rotina do paciente, procedimentos invasivos que podem ser tomados de forma agressiva por ele. $\mathrm{O}$ sujeito tem sua fragilidade exposta para si e para o outro; é lançado em um estado de desamparo, revelando a precariedade da condição humana diante do imprevisível (Moura, 2000, p. 9).

Quando este corpo é submetido a procedimentos, intervenções e discursos que o fazem meramente corpo, a ação do analista intenciona produzir como efeito um corpo-falante, ou seja, fazer emergir no nomeável ou no inominável - pois no silêncio, no grito e no choro também se encontra (ou se revela) um sujeito. Esses eventos, presentes nos hospitais, inerentes ao adoecimento, por serem inesperados, vacilam as certezas e as respostas dos sujeitos. Em um primeiro momento, marcado pelo excesso da realidade, pode ser difícil ao sujeito, ou até impossível, suportar isso que se experimenta na própria pele. Mas, como o aparelho psíquico está em constante constituição, em constante processo de mudança, o adoecimento não consistirá, stricto sensu, em um evento que limita ou anula a existência do sujeito. 
Trazemos, então, uma intervenção clínica que ilustra como o adoecimento e a hospitalização prolongada podem ter efeitos sobre o sujeito enquanto desejante, enquanto corpo vivo. A intervenção do analista junto à sua família propicia uma mudança no posicionamento dela diante do paciente, o que pode ter consequências sobre o mesmo.

\section{Há lugar}

Dos encontros marcantes que redimensionam nosso trabalho, relatamos a seguir o caso de quem ficticiamente denominamos Vitor. Os atendimentos foram realizados na Unidade de Tratamento Intensivo (UTI) de um hospital privado na cidade de Juiz de Fora (MG), onde o serviço de psicologia acolhe os pacientes e seus familiares, podendo este acolhimento se desdobrar em um atendimento.

Vitor, um senhor de 89 anos com variadas complicações de saúde, alternava entre a necessidade de internações na UTI e a alta para o leito comum, estando, desta forma, há um tempo prolongado fora de casa. Os atendimentos a seguir descritos decorreram em uma das internações de Sr. Vitor na UTI, quando seu quadro clínico exigiu que fosse sedado e entubado.

Com sua chegada na unidade, Vitor, Dona Noá (sua esposa) e Natália (sua filha) - todos ficticiamente nomeados - foram acolhidos. Natália, diante do pai, acamado, sedado e entubado, ao se deparar com a presença da analista, não pôde compreendê-la e de imediato indagou: "o que faz você aqui?".

Seu pertinente questionamento, ao qual poderia ser objetivamente respondido com as tarefas desempenhadas pelo psicanalista na unidade, foi sucedido por um breve silêncio. Em poucos instantes, Natália se ocupou de responder: "você vem para dar apoio aos familiares, né?" Natália não vislumbrava nada que a psicanalista pudesse fazer em relação ao seu pai. Quando questionada sobre o apoio a que se referia, tanto Natália quanto D. Noá manifestaram um cansaço, não só físico, desencadeado pela rotina de cuidados e internações de Sr. Vitor. Ambas "confessavam", em suas palavras, uma "conduta de entrega" de Sr. Vitor, para a "outra dimensão", vislumbrando o momento em que poderiam, os três, "descansar". Elas diziam que Sr. Vitor já não devia aguentar mais a situação de internação, que ele sempre voltava à UTI, ficava à beira da morte, mas os médicos conseguiindo reverter o quadro, permitiam que ele "ganhasse uns dias".

Sr. Vitor respondeu bem às interações medicamentosas e, em pouco tempo, iniciou o desmame dos sedativos. À beira do leito, sua família se dirigia a ele, conversava, diziam que não quereriam vê-lo sofrer, que se estruturariam na sua ausência, que ele não deveria se preocupar, que não precisava lutar para viver. Sr. Vitor já estava há alguns dias sem os sedativos e não havia ainda acordado. Tanto a esposa como a filha o viam como morto, falavam dele conjugando verbos no passado, como se ele não estivesse (no) presente. Quando se perguntava a elas sobre ele, suas características e seus gostos, respondiam apenas sobre seu estado de saúde debilitado, sobre suas limitações... era o que conseguiam enxergar. Até que, quando questionadas a respeito da vida de Sr. Vitor, sem titubear, Natália respondeu que ele sempre amou viver, disse a filha. A analista dá 
destaque a essa frase. Sr. Vitor empenhava-se muito para manter-se em vida. Demarcado este fato pela analista, D. Noá e Natália, com expressão de susto, desconcertadas, riram e nada mais disseram.

Nos dias seguintes, a cena que se observava no leito de Sr. Vitor era outra, o discurso havia se modificado: "papai, acorda! O dia está lindo, vem ver!". Em poucos dias, Sr. Vitor abriu os olhos, acordou, foi (vi)ver. Logo em seguida, com papel e caneta se comunicava com sua família, escrevia e registrava suas palavras, sua presença. Em pouco tempo, teve alta da unidade. Neste dia, Natalia disse que havia compreendido porque seu pai "sempre voltava", que não eram apenas os médicos quem revertiam o quadro, era também ele. Sr. Vitor não era mais quem "ganhava alguns dias", era quem "lutava pelos seus dias". Ela o apelidou de "Fênix", aquele que ressurge das cinzas.

\section{Considerações Finais}

Com a experiência da escuta analítica em um contexto hospitalar, verificou-se a particularidade de sua função: dar lugar ao sujeito - seja ele o paciente, o médico, a equipe ou a família - no que tange a especificidade da sua dor. Desta forma, desvenda-se não só o lugar do analista, mas uma infinidade de lugares reservados à essa prática - do um a um, lugar flexível, que transita e permite movimento. O lugar do movimento. Um lugar que movimenta.

Observamos, nesta e em outras circunstâncias, que quanto mais se exclui o sujeito, mais a psicanálise se faz necessária (Batista et al., 2011, p. 100). O "não há nada a fazer" é convertido em possibilidade de trabalho (Figueiredo, 2000, p. 94). o "ofício impossível" não só se torna possível como também cria condições de possibilidade ao sujeito.

Ao propor este encontro com o sujeito, o analista permite a criação de um espaço de escuta, o que gera efeitos na implicação do sujeito com o que diz, com seu adoecimento, com o que se queixa. Não se pode dizer que neste contexto de atuação, nas instituições hospitalares, o analista objetiva estabelecer condições para o desenvolvimento de uma análise propriamente dita. Suportando os outros discursos - no literal sentido da palavra, como aquele que suporta e fornece suporte - o analista adentra as instituições de saúde visando ofertar o discurso analítico (Salinas \& Santos, 2002, p. 188).

Se estamos distantes de uma prática prescritiva, das ordens universais, e mais próximos da emergência da verdade do sujeito, do particular, conseguimos sustentar um espaço frutífero tanto para o paciente como para a equipe, um lugar que acolhe as impossibilidades e trabalha a partir delas. Tão raro nos dias de hoje.

\section{Notas}

1. Este artigo é um desdobramento do trabalho de conclusão do curso de graduação em psicologia de Juliana Andrade Salgado intitulado "O que faz você aqui?": indagações ao psicanalista das instituições hospitalares, orientado pela Profa. Dra. Alinne Nogueira Silva Coppus, e apresentado na Universidade Federal de Juiz de Fora em 2017. 


\section{Referências Bibliográficas}

Batista, G., Decat de Moura, M. \& Borges de Carvalho, S., (2011). Psicanálise E Hospital 5: A Responsabilidade Da Psicanálise Diante Da Ciência Médica. Rio de Janeiro: Wak Editora.

Batista, G., \& Rocha, G. M. (2013). A presença do analista no Hospital Geral e o manejo da transferência em situação de urgência subjetiva. Revista da SBPH, 16(2), 25-41.

Coppus, A. N. S., \& Netto, M. V. R. F.. (2016). A Inserção do Psicanalista em uma Unidade de Tratamento Intensivo. Psicologia: Ciência e Profissão, 36(1), 88-100.

Figueiredo, A. C. (2000). Vastas confusões e atendimentos imperfeitos: a clínica psicanalítica no ambulatório público. $2 \mathrm{a}$ ed. Rio de Janeiro: Relume-Dumará.

Freud, S. (1996a). Sobre o inicio do tratamento (Novas recomendações sobre a técnica da psicanálise I). In J. Salomão (Trad.) Edição standard brasileira das obras psicológicas completas de Sigmund Freud (Vol. 12, pp. 163-187). Rio de Janeiro: Imago. (Trabalho publicado em 1913).

Freud, S. (1996b). Uma breve descrição da psicanálise. In J. Salomão (Trad.) Edição standard brasileira das obras psicológicas completas de Sigmund Freud (Vol. 19, pp. 111-125). Rio de Janeiro: Imago. (Trabalho publicado em 1923-1925).

Lacan, J. (1980). La tercera. In: Actas de la Escuela Freudiana de Paris (pp. 159-186). Barcelona: Ediciones Petrel (Originalmente publicado em 1974).

Lacan, J. (1988). Seminário. Livro 11: os quatro conceitos da psicanálise. Rio de Janeiro: Jorge Zahar. (Originalmente publicado em 1964)

Lacan, J. (1992) Seminário 17: o avesso da psicanálise. Rio de Janeiro: Jorge Zahar (Originalmente publicado em 1969-1970)

Machado, M. Do V., \& Chatelard, D. S.. (2012). A difusão da psicanálise e sua inserção nos hospitais gerais. Tempo psicanalitico, 44(2), 445-467.

Miller, J.-A. (1999). As contraindicações ao tratamento psicanalítico. Opção lacaniana, Revista Brasileira Internacional de Psicanálise, São Paulo, v. 25, 52-55.

Morais, J. L., Rei, V. A. F., \& Nicolau (2009). R. F. A clínica psicanalítica no hospital geral: uma escuta possível. Colóquio Internacional sobre o Método Clínico, São Paulo, Recuperado de http://docplayer.com.br/199295-A-clinica-psicanalitica-no-hospital-geral-uma-escutapossivel.html.

Moura, M. D. (2000). Psicanálise e Hospital. 2ed. Rio de Janeiro: Revinter.

Moura, M. D. (2005). Psicanálise e Hospital 4. Novas versões do pai: Reprodução assistida e UTI. Belo Horizonte: Autêntica.

Moura, M. D., \& Souza, M. C. B. (2007). Psicanálise e hospital: se ao "a" deve o analista chegar, por onde andava ele? Epistemo-somática, Belo Horizonte, v.4, n.2, 9. 127-138.

Rinaldi, D. (2002). O desejo do psicanalista no campo da saúde mental: problemas e impasses da inserção da psicanálise em um hospital universitário. In: D. Rinaldi, \& M.A.C. Jorge 
(Orgs.). Saber, verdade e gozo: leituras de O Seminário, livro 17 de Jacques Lacan. Rio de Janeiro: Rios Ambiciosos, pp.53-69

Salinas, P., \& Santos, M. A. dos. (2002). Serviço de triagem em clínica-escola de psicologia: a escuta analítica em contexto institucional. Psychê, 6(9), 177-196.

Torezan, Z. C. Facci, \& Rosa, A. da C. (2003). Escuta analítica no hospital geral: implicações com o desejo do analista. Psicologia: Ciência e Profissão, 23(2), 84-91.

Citação/Citation: Andrade Salgado, J. \& Silva Coppus, A. N. (nov. 2020 a abr. 2021). Percursos e entraves dos psicanalistas nos hospitais. Revista aSEPHallus de Orientação Lacaniana, 16(31), 69-79. Disponível em www.isepol.com/asephallus. Doi: 10.17852/1809-709x.2021v16n31p69-79

Editor do artigo: Tania Coelho dos Santos.

Recebido/Received: 10/03/2020 / 03/10/2020.

Aceito/Accepted: $10 / 28 / 2020$ / 28/10/2020

Copyright: (c) 2019 Associação Núcleo Sephora de Pesquisa sobre o moderno e o contemporâneo. Este é um artigo de livre acesso, que permite uso irrestrito, distribuição e reprodução em qualquer meio, desde que o autor e a fonte sejam citados/This is an open-access article, which permites unrestricted use, distribution, and reproduction in any medium, provided the author and source are credited. 